\title{
The Perception of Iranian EFL Teachers towards the Application of Computer Assisted Language Learning
}

\author{
Ghane Mohammadi 1 \\ Mohsen Masoomi 2 \\ ${ }^{1}$ Department of English Language, Kurdistan Science and Research Branch, Islamic Azad University, Sanandaj, Iran \\ 2 Department of English Language, Sanandaj Branch, Islamic Azad University; Sanandaj, Iran \\ ${ }^{1}$ ghane.mohammadi@yahoo.com, ${ }^{2}$ masoomi.mohsen@outlook.com
}

Doi:10.5901/mjss.2015.v6n5s1p228

\begin{abstract}
There is no doubt in the influential role of Computer-assisted language learning (CALL) in language learning in new ages of technology. And in line with this, the people' perceptions and acceptance of the information and computer technology (Rogers, 1983) is regarded as the most essential matter according to the theories that consider human agency, for this reason, upcoming study considers teachers' perceptions on the widely or constantly flourishing teaching techniques and language learning approaches utilizing the current practical kinds of learning as computer-assisted language learning in the specific English language institutes in Kurdistan. Iran. The reason for which this study is done was to investigate the usage and perception of Iranian English Language teachers of English language institutes in Kurdistan towards the application and more demand for using computer technology in EFL courses. In line with this subject as the main purpose, the study also discussed in detail Iranian teachers' perceptions towards computer and related information technology and factors and circumstances that plays a part in their perceptions in order to get some utilizable findings and constructive suggestions for the undertaking and application of the experiences in using computer-assisted language learning to their language teaching. To achieve this aim, 96 EFL teachers in Kurdistan province, Iran (male \& female) participated in this study. They were selected based on randomly selection to participate in this study. First of all, as the main instrument of research an open-ended questionnaire was given to participants in the study in order to check their views about current state of computer assisted language learning and their views on how they prefer using technology in their teaching. The study provided good contribution to define the essence of issue and a body of knowledge concerning the extent of using computer and also, with regard to the significance of teachers' perceptions for the use of CALL in educational direction. After this stage all the data were collected and analyzed and the relationship between variables presented.
\end{abstract}

Keywords: Teachers' perception, computer- assisted language learning (CALL); Technology.

\section{Introduction}

Computer assisted language learning (CALL) is both exciting and frustrating as a field of research and practice. It is exciting because it is complex, dynamic and quickly changing and it is frustrating for the same reasons (Hubbard, 2009).

Information and using technology as the inevitable dimension of our life expands the contemporary and current field of second language learning which needs innovative skills and knowledge for more interested people who are seeking to put together all of its practical aspects into their well-qualified and professional practice or perceive the significance its influence on the language learner and teacher. Nevertheless the technology undergoes significant changes which CALL information, knowledge and techniques and proficiency must be regularly regenerate to stay in line with the field.

So it is a well-established fact that Computer-assisted language learning (CALL) contributes to create a functional and suitable learning environment in order that students can incorporate themselves in a circumstance full of interaction to apply multimedia content, in company with the supervision and guidance of teachers.

In this age of technology and using computers in all aspects of our life, there are a number of studies in the fields of teaching and on teachers' perceptions and the application of technology specially computers in developed countries, although less studies have been conducted significantly focusing on perception towards CALL in some developing countries like Iran, these promises of the new world have created a comprehensive speculations for applying educational reforms that promote us to use new tools.

Therefore, paying attention to these details, one of the significant aspects that language teachers follow in their educational programs is language teachers technology which prepare for teachers some new strategies and skills to help 
their learners promote their learning in mastering new foreign language more easily and in an organized and better manner. A

In the greater parts of studies on teacher technology education following issues are investigated(Egbert \& Trena, 2002): what teachers are and/or should be learning in technology courses (Hargrave \& Hsu, 2000; Johnson, 1999); students' knowledge, teacher-education of perception toward technology (Atkins \& Vasu, 2000; Milbraith \& Kinzie, 2000); and a study about how teachers think about and use computers in the classroom (Ertmer, Addison, Lane, Ross, \& Woods, 1999; Levy, 1997;Pilus,1995; Walker, 1994).

Therefore, the purpose of this study is to present the Iranian teachers' perception and beliefs according the finding of a study to know the extent of computer application among teachers in Kurdistan province, Iran.

Along with this, the study investigates the perception of teachers towards the application of computer related to the educational purposes as the main purpose.

\section{Method}

\subsection{Participants}

The participants who took part in the present study were English foreign language teachers with the different extent of experience from different well-known English language institutes in Kurdistan province, during 2013 -2014.

The samples of 96 subjects were randomly selected to participate in this study according to Corcoran Formula as the specific procedure used in researches as sample selection. They all volunteered to fill out the questionnaire about their perceptions and application of the computer technology in the class.

Priority of concern were on CALL experience in English language learning and along with it some background information like gender ,age, education and teachers experiences were highlighted because all of these give better and clear insights about teachers overall perception of Computer assisted language learning. The background information of the participants is represented in Table 1.1.

Table 1.1: The exact Background information about the respondents of teachers to questionnaire

\begin{tabular}{|c|c|}
\hline Variables & $\mathrm{N}=96$ \\
\hline Age sd-average (minimum.-maximum) & $5.59408-29.0313(21-49)$ \\
\hline \multicolumn{2}{|c|}{ Age Groups $[n(\%)]$} \\
\hline 20 - 25 years old & $26(27.1)$ \\
\hline $26-30$ years old & 40 (41.7) \\
\hline $31-35$ years old & $18(18.8)$ \\
\hline $36-40$ years old & $8 \quad(8.3)$ \\
\hline 41 and highest years old & $4 \quad(4.2)$ \\
\hline \multicolumn{2}{|c|}{$\operatorname{Sex}[n(\%)]$} \\
\hline Male & $46(47.9)$ \\
\hline Female & $50(52.1)$ \\
\hline \multicolumn{2}{|c|}{ Teaching Experience (years) [n(\%)] } \\
\hline $1-4$ & $45(46.9)$ \\
\hline $5-8$ & $33(34.4)$ \\
\hline $9-12$ & $11(11.5)$ \\
\hline $13+$ & $7(7.3)$ \\
\hline
\end{tabular}

$\mathrm{n}$ : case number, sd: standard deviation

The participants 'average age is 29.0313 years ( $\mathrm{sd}=5.59408$ ), with a range extends from 20 to 50 years old. The ratio of the males $47.9(n=46)$ to the females $52.1(n=50)$ is to more extent equal and in a normal distribution and for practical reasons the sample in population is divided into five age group(20-25,26-30,31-35,36-40,and highest years old) with four teaching experience(1-4,5-8,9-12,13 and highest years).

It can be concluded based on the results that a great number of participants $(46.9 \%)$ have been engaged in teaching English for 1 to 4 years ,(34.4\%) for 5 to 8 years and (11.5\%) for 9 t0 12 and (7.3\%) for 13 and highest.

Of all participants $65.6 \%(n=63)$ of them have bachelor degree in ELT and $32.3 \%(n=31)$ of them have master degree and $2.1 \%$ ( $n=2)$ of them are student or graduated of other fields. 


\subsection{Instrumentation}

The design adopted in the present study is quantitative research methodology.

The design of the teachers' perception toward computers questionnaire which is conducted in this study was inspired by reviewing the previous studies which have examined the perceptions of teachers on the application of CALL (Rhonda, Christensen, Gerald. Knezek; 2009) .

The questionnaires were composed of five sections to check teachers' perception and to understand their views towards the application of computer assisted language learning.

Table 1.2 shows the factors that have been investigated and number of questions for different questionnaires 'section.

Table 1.2: The number and the kinds of questions on the questionnaires

\begin{tabular}{|l|c|c|c|c|c|}
\hline Sections & Section 1 & Section 2 & Section 3 & Section 4 & section 5 \\
\hline Question Types & Computer perception & computer attributes & cultural perceptions & computer competence & computer access scale \\
\hline NQ & 20 & 18 & 16 & 15 & 3
\end{tabular}

Note: NQ: number of questions.

Before addressing the research questions, it was necessary to investigate the reliability of the questionnaire. So for the questionnaire applied in this study a pilot study was conducted and a group of EFL teachers were asked in Kurdistan English institutes, later on final modifications were made. And a panel of experts included some experts in bilingual, measurement and Professors of educational technology established and evaluated the face and content validity of questionnaire.

According the finding from experts the six scales in questionnaire are appropriate to achieve the particular purpose in investigation of the content areas and the context of the study from two cultural and technical dimensions.

The reliability of the questionnaire was calculated by using the Statistical Packages for Social Sciences (SPSS) Version 17.0. And the Cronbach alpha was used in this study; it is for the first four scales. It can range from .00 to 1.00. That is shown in Table 1.3.

Table 1.3: Reliability for the first four scales of questionnaire

\begin{tabular}{|l|c|c|}
\hline Scale & Number of items & reliability \\
\hline computer perception & 20 & 0.86 \\
\hline computer attributes & 18 & 0.72 \\
\hline cultural perceptions & 16 & 0.71 \\
\hline computer competence & 15 & 0.89 \\
\hline
\end{tabular}

Also in order to ensure suitability's questionnaire for the participants in Iranian context, questionnaire has been translated into native language of the teachers in Iran and then back into English. The estimation of the reliability before and after this translation showed the similar results

\subsection{Procedure}

In order to conduct the study first of all, ninety six teachers who took part, required to fill out the questionnaire.

The researcher distributed the questionnaires directly to respondents. The way of filling out the questionnaires, purposes and significance of their responses were explained to participant to motivate them. The questionnaires were completed by all of the participants, and the analysis of data have been done via the Statistical Packages for Social Sciences (SPSS) Version 17.0

After analyzing specific items in questionnaire using the Statistical Packages for Social Sciences (SPSS) Version 17.0 for Windows, the researcher were used the descriptive statistics in order to obtain basic features of the data in the study and to provide simple summaries about the samples and the measures.

By consideration of the five sections in questionnaire, the findings of the results got together and analyzed from the statistical analysis of the questionnaires .First of all as there is in descriptive analysis, the data were analyzed through 
frequency, mean, percentage, and standard deviation values. Based on the information, the rationale behind the use of descriptive statistics and also t-test of one sample mean (some researcher name it as population t-test), were to evaluate this reality between teachers that whether they have right and positive perceptions toward Computer assisted, and the factors affected by this positive perceptions.

And finally in order to find the significant level in median scores in answers for the Likert- scale items among independent groups in teachers' perception towards the application of CALL in English learning and teaching, independent sample t-tests were the appropriate statistical method to estimate the level of the difference among participants in terms of their gender.

The research questions are restated. Then, the quantitative data are computed and analyzed separately to provide answers to research questions. All numerical calculations and estimations were done by using the Statistical Packages for Social Sciences (SPSS) Version 17.0.

\subsection{Restatement of the Research Questions}

\subsubsection{Results for the first research question}

1- What's the overall perception of Iranian EFL teachers towards the application of CALL?

In the first research question, the responses of participants to 20-item scale composed in three sections that evaluates domains of perception (the cognitive, affective and behavioral) were examined and the distribution of mean scores related to the results are shown in table 2.1

As table 2.1 shows, it can be asserted that the teacher participants have a positive perception towards ICT according to the overall mean score of $4.2(\mathrm{sd}=0.53)$,.

Table 2.1: The perception toward CALL scale according to the distribution of mean scores

\begin{tabular}{|l|c|c|c|c|c|c|c|}
\hline \multirow{2}{*}{ Scale } & \multicolumn{5}{|c|}{ Percentage } & \multirow{2}{*}{ Mean } & \multirow{2}{*}{ SD } \\
\cline { 2 - 6 } & SD & D & N & A & SA & & \\
\hline Affect & 0.0 & 2.0 & 5.2 & 44.8 & 47.9 & 4.3 & .68625 \\
\hline cognition & 0.0 & 0.0 & 29.2 & 63.5 & 7.3 & 3.7 & .56574 \\
\hline behavior & 0.0 & 0.0 & 3.1 & 56.3 & 40.6 & 4.3 & .54772 \\
\hline Overall perception & 0.0 & 0.0 & 4.2 & 63.5 & 32.3 & 4.2 & .53711 \\
\hline
\end{tabular}

SD, strongly disagree (1); D, disagree (2); N, neutral (3); A, agree (4); SA, strongly agree (5).

As we can consider based on the distribution of mean scores towards CALL in table 2.1 the initiation into the innovation decision process has been shown by Teachers' certain positive perception towards ICT (Rogers, 2003). This finding proves that the Knowledge and Persuasion stage is a stepped stage for Iranian teachers (Rogers, 2003) and probably they are ready to experience the decision.

This is precisely the point that numerous theorists have demonstrated, perceptions can regularly predict future behaviors of the participants and all the subject population (Ajzen \& Fishbein, 2005). Therefore, it can be resulted that teachers who show positive perception towards CALL, to more extent utilize computer and technology in their instructional and administrative tasks if it change into a required course and more accessible to them. In such circumstances, what might affect their perception toward computer use is teachers' expertise in using computer and social and cultural supports from others (colleagues, peers, etc.) that there is in his/her work environment.

In addition, in the case of the affective domain, based on obtained data it was observed that more of the participants (92.7 \%) their feelings about using ICT in education was good, and they enjoy using computer in the process of their teaching. On the contrary, little negative feelings (just2 \%) reported among teachers about ICT as an educational tool.

In the cognitive area, around $70.8 \%(\mathrm{SD}=0.56)$ there was this belief among teachers that computer contributes to promote students 'learning and gives quick and simple access to information

So, based on what has been shown by results of the questionnaire, the highest mean score among the three subscales of perception scale is related to the affective and behavior domain( $M=4.3)$, this proves the positive emotional feeling of computer in education among teachers.

Based on obtained data a remarkable number of English language teachers (96.9\%) highlights the points of interest to the benefits of teaching using technology and computers and asserts that computer save their time and effort 
and help them to achieve the effective learning/teaching environment.

Expressing doubts about the impact of technology and especially computers on the level of students' motivation or expected potentials of technologies related with teaching practices was the participants 'responds to behavioral domain, they were the smallest portion of the attendants(3.1\%).

Accordingly, the greater amount of the respondents stated that they appreciate and have good feelings in using CALL either in general and education.

Also the results obtained from t-test of one sample mean verified that the perception of EFL teachers towards the application of CALL is significantly positive. The findings and results of these analyses are presented in Table 2.2 .

Table 2.2: A population t-test analysis of whether teachers' perception towards the application of CALL is significantly positive

\begin{tabular}{lcccl}
\hline Variable & Mean (Test Value) & SD & Sig.( 2-tailed) & Mean difference \\
\hline Affect & 4.3 & .68625 & .226 & .08542 \\
Cognition & 3.7 & .56574 & .163 & .08125 \\
Behavior & 4.3 & .54772 & .183 & .07500 \\
Overall perception & 4.2 & .53711 & .142 & .08125 \\
\hline
\end{tabular}

* Significant $(p<.05)$;

According to these results, teachers' perception is significant at the level of $P \leq 0.05$.

Affective domain, $(M=4.3)$, cognitive domain, $(M=3.7)$, behavioral domain, $(M=4.3)$, Overall perception, $(M=4.2)$.

\subsubsection{Results for the second research question:}

Since the second research question was too broad to be investigated as one; therefore it was translated into more specific items, which gave 5 research questions: the first of which is:

"What are the teachers' perceptions towards CALL in terms of computer attributes? "

\subsubsection{Results for research question 2a: Computer attributes}

Teachers' perceptions regarding the computer attributes as an important factor forming teachers' perception towards the use of ICT is what is investigated in the second question.

The section of questionnaire related to these attributes was 18 statements divided to four groups of responses investigating different factors related to the perception, namely from the beginning, statements about relative advantage (items 1-5), the level of compatibility (items 6-10) the level of complexity (items 11-14), and the level of observability (items 15-18).

Generally to get the exact results, before the analysis was carried out negative statements were reverse-coded. The mean scores of this section are presented in table 2.3.

Table 2.3: Distribution of mean scores on the scales related to computer attributes.

\begin{tabular}{|c|c|c|c|c|c|c|c|}
\hline \multirow{2}{*}{ Scale } & \multicolumn{5}{|c|}{ Percentage } & \multirow{2}{*}{ Mean } & \multirow{2}{*}{ SD } \\
\hline & SD & D & $\mathbf{N}$ & A & SA & & \\
\hline Advantage & 0.0 & 0.0 & 1.0 & 36.5 & 62.5 & 4.1 & .51031 \\
\hline Compatibility & 0.0 & 2.1 & 19.8 & 67.7 & 10.4 & 3.8 & .60905 \\
\hline Complexity & 3.1 & 9.4 & 54.2 & 29.2 & 4.2 & 3.2 & .79741 \\
\hline Observability & 0.0 & 0.0 & 8.3 & 14.6 & 77.1 & 4.6 & .62091 \\
\hline Overall attributes & 0.0 & 0.0 & 14.6 & 83.3 & 2.1 & 3.8 & .39068 \\
\hline
\end{tabular}

$\mathrm{SD}$, strongly disagree (1); D, disagree (2); N, neutral (3); A, agree (4); SA, strongly agree (5).

As we can consider in table 2.3, relative advantage of computers allocates the highest mean in computer attribute scale $(M=4.1, S D=0.51)$. Correspondingly, more of the respondents confirm that they get real advantages with teaching with computers in contrary to traditional methods of instruction.

As a matter of fact, computer can provide appropriate and adequate solutions for the problems that are resulted 
from on-the-job (Felton,2006).

For statements that were negative, about $99 \%$ disagreements with this case that "computers are not useful for language learning "was expressed by participants and the level of agreement among the participant was only $1 \%$.and we received relatively high and positive perception of the participants $(78.1 \%)$ to the compability of teaching practices with computers $(M=3.08, S D=0.60)$. and the fitness of the curriculum goal by those who use computer was in a high level based on what they expressed (78.1\%)

Although, the participants expressed their agreement on the limitations that exist in class time when they use computers, regarding the complexity of the computers and the level of the teachers perception the mean score of 3.02 $(S D=0.79)$ was found that indicates more than half of the teachers perceive the application of computer easy and appropriate and Iranian teachers doesn't have more problem with using computers and definitely they are comfortable with using such technologies in their English institutes and schools.

However they accept for learning computers they need to do some efforts.

In the last factor related to computer attributes, the level of observability in the score of the participants' responses is $4.6(\mathrm{SD}=0.62)$ and this is relatively highest among the other attributes and showed the positive advantage of ICT.

Also the results obtained from t-test of one sample mean verified that teacher's perception for separate factors in the computer attributes is significantly positive. The results of these analyses are presented in Table 2.4

Table 2.4: A population t-test analysis of whether teachers' attribute towards the application of CALL is significantly positive

\begin{tabular}{lcccc}
\hline Variable & Mean (Test Value) & SD & Sig.( 2-tailed) & Mean difference \\
\hline Advantage & 4.1 & .51031 & .134 & .51458 \\
Compatibility & 3.8 & .60905 & .301 & .06458 \\
Complexity & 3.2 & .79741 & .818 & .01875 \\
Observability & 4.6 & .62091 & .171 & .08750 \\
Overall attributes & 3.8 & .39068 & .063 & .07500 \\
\hline
\end{tabular}

* Significant $(p<.05)$;

\subsubsection{Results for research question $2 b$ : Cultural perceptions}

The second one:

"What are the teachers' perceptions towards CALL in terms of cultural perceptions? "

16 Likert-type statements about the factors that define respondents' cultural perceptions

Towards the application of computers and its impacts on Iranian society and English language institutes were asked to respond.

This questionnaire was developed by Albirini (2006). In the questionnaire that he developed and were used in this study the rating of the cultural perceptions on each item was from "strongly disagree" (1) to "strongly agree" (5), and the range of possible mean scores is between 1 and 5, so the higher scores in this rage indicates the highest and positive cultural perceptions.

Table 2.5: Distribution of mean scores on the cultural perceptions scale

\begin{tabular}{|l|c|c|c|c|c|c|c|}
\hline \multirow{2}{*}{ Scale } & \multicolumn{5}{|c|}{ percentage } & \multirow{2}{*}{ Mean } & \multirow{2}{*}{ SD } \\
\cline { 2 - 6 } & SD & D & N & A & SA & & .39068 \\
\hline Cultural perceptions & 0.0 & 0.0 & 14.6 & 83.3 & 2.1 & 3.8 & .39 \\
\hline
\end{tabular}

SD, strongly disagree (1); D, disagree (2); N, neutral (3); A, agree (4); SA, strongly agree (5).

The overall mean calculated in the questionnaire's finding on the cultural perceptions scale as can be seen in this table (Table 2.5) was 3.8 (SD: 0.39)that represents the teacher's perception towards the relevance and impact of ICT and computer to their culture in Iranian society and English language institutes is positive .

Therefore, teachers did not care about ICT because it doesn't make a threat against Iranian culture. This point was confirmed because the respondents of the majority of the teachers showed positive (83.3\%) or highly positive (2.1\%) degree of perceptions about the applicability of CALL to Iranian community and institutes.

Based on what the respondents showed the application of computers will increase and improve the specific 
standards of living and do not increase their dependency on foreign countries,

Also the results obtained from t-test of one sample mean verified that the teachers' perception about the relevancy of CALL to Iranian community and English language institutes is significantly positive. The results of these analyses are showed in Table 2.6.

Table 2.6: A population t-test analysis of the cultural perceptions scale towards the application of CALL.

\begin{tabular}{lcccc}
\hline Variable & Mean (Test Value) & SD & Sig.( 2-tailed) & Mean difference \\
\hline Cultural perceptions & 3.8 & 39068 & .063 & .07500 \\
\hline
\end{tabular}

\subsubsection{Results for research question 2C: Computer competence}

The third one:

"What are the teachers' perceptions towards CALL in terms of computer competence? "

In this part of questionnaire 15-items investigate the computer competence of the participants on a 4-point, scale ranging from 1 with (no competence) to 4 (much competence).in table 2.7 the distribution of mean scores was shown according to the level of the computer competence.

As another important factor related to overall perception, the computer competence scale was utilized to assess English language teachers' overall perceptions in the level of their knowledge and performance in using computer. This scale was developed by Albirini (2006).

Table 2.7: Distribution of mean scores on the computer competence scale

\begin{tabular}{|l|c|c|c|c|c|c|}
\hline \multirow{2}{*}{ Scale } & \multicolumn{3}{|c|}{ percentage } & \multirow{2}{*}{ Mean } & SD \\
\cline { 2 - 7 } & No competence & Little competence & Moderate competence & Much competence & & \\
\hline Computer competence & 0.0 & 20.8 & 44.8 & 34.4 & 3.1 & .73441 \\
\hline
\end{tabular}

SD, strongly disagree (1); D, disagree (2); N, neutral (3); A, agree (4); SA, strongly agree (5).

The great number of teachers claims that they had moderate (44.8\%) or much (34.4\%) computer competence and they can use most of their needed functions in computers.

Twenty point eight (20.8\%) of the respondents expressed their little computer competence and zero\% (0.0\%) possessed no definite competence in using computers. On the average, the data obtained from respondents asserted that they showed "Moderate Competence" in the using of computers(Mean $=3.1 ; \mathrm{SD}=0.73441$ ) in computer uses, these include how to install software, the usage of printer, the evaluation that has been done with educational software ,productivity software, the application of graphic, keeping the grades and virus removal.

Also the results obtained from t-test of one sample mean verified that the teachers' competence in using computers is significantly positive. The results of these analyses are presented in Table 2.8 .

Table 2.8: A population t-test analysis of whether teachers' computer competence to application of CALL is significantly positive

\begin{tabular}{lcccc}
\hline Variable & Mean (Test Value) & SD & Sig.( 2-tailed) & Mean difference \\
\hline Computer competence & 3.1 & .73441 & .638 & .03542 \\
\hline
\end{tabular}

According to these results, teachers' competence in application of technology and computers among Iranian EFL teachers is significant at the level of $P \leq 0.05$

\subsubsection{Results for research question 2D: Computer access}

The fourth one:

"What are the teachers' perceptions towards CALL in terms of computer access? "

In this section of questionnaire, the level of access to computers by teachers were asked

The statements of the questionnaire related to computer access are: (a) the place of the using computers by 
teachers and instructors (at home, in the office, and at school), and (b) the times of access to computers (never, once a month, once a week, two to three times a week and daily).

The level of access to computers by teachers was presented by a statistical mean score from 1 (Never) to 5 (Daily)

Table 2.9: Distribution of mean scores on the computer access scale

\begin{tabular}{|l|c|c|c|c|c|c|c|}
\hline \multirow{2}{*}{ Scale } & \multicolumn{4}{|c|}{ Percentage } & \multirow{2}{*}{ Mean } & \multirow{2}{*}{ SD } \\
\cline { 2 - 7 } & Never use & Once a month & Once a week & 2-3 times a week & Daily & & \multicolumn{1}{c|}{ (1.0 } \\
\hline Home & 0.0 & 1.0 & 1.0 & 16.7 & 81.3 & 1.2 & .50686 \\
\hline School \& English language institutes & 14.6 & 11.5 & 10.4 & 18.8 & 44.8 & 2.3 & 1.49733 \\
\hline $\begin{array}{l}\text { Other (internet cafe's, friends, } \\
\text { relatives, university, work) }\end{array}$ & 32.3 & 26.0 & 14.6 & 3.1 & 24.0 & 3.3 & 1.55245 \\
\hline Overall access level & 0.0 & 3.1 & 37.5 & 40.6 & 18.8 & 2.2 & .79472 \\
\hline
\end{tabular}

$\mathrm{SD}$, strongly disagree (1); D, disagree (2); N, neutral (3); A, agree (4); SA, strongly agree (5).

Based on this table (Table 2.9), the level of mean score of the overall Computer access scale was $2.2(\mathrm{SD}=0.79)$, which suggests that, on the average; English language institute teachers had access to a computer almost once a week. Additionally, results obtained from this section demonstrated that only $18.8 \%$ of teachers, the computer were accessible for them daily.

As we can conclude from the results of the questionnaire in this section regular and quick access to computer to get data like student's educational documents and their marks, writing class timetables, and the process of teacher's evaluation has a priority for teachers.

Additionally, teachers demonstrated their high access to technology and computer in outside of home and educational environment such as internet café's $(M=3.3)$ and at their institutes $(M=2.3)$.

This degree of the access to computers by teachers can be relatively a positive sign.

Also the results obtained from t-test of one sample mean verified that the teachers' access in using computers is significantly positive. The results of these analyses are presented in Table 2.10.

Table 2.10: A population t-test analysis of whether teachers' computer access towards the application of CALL is significantly positive

\begin{tabular}{lcccc}
\hline Variable & Mean (Test Value) & SD & Sig.( 2-tailed) & Mean difference \\
\hline At home & 1.2 & .50686 & .718 & .01875 \\
School & 2.3 & 1.49733 & .881 & .02292 \\
Other & 3.3 & 1.55245 & .547 & .09583 \\
Overall access & 2.2 & .79472 & .539 & .05000 \\
\hline
\end{tabular}

According to these results, teachers' access of technology and computers among Iranian EFL teachers is significant at the level of $\mathrm{P} \leq 0.05$

\subsection{Results for the third research question: Effects of Gender on EFL Teachers' perception towards CALL}

Based on statistical explanations, inasmuch as T- tests and One-way ANOVA Tests can be applied in data which represents a normal distribution of responses, in the present study the researcher ran an Independent T-Test to examine whether in terms of their gender there was any differences among the given responses of participants.

The obtained results demonstrated that there was no critical distinction among the participants' responses in terms of their gender. In Table 4.11 we can consider the obtained results from participants of the research.

According to Leven' Test for calculation of the equality of variances and T-test for evaluation of the equality of means and based on the significant value of the test we accept that the variance and mean of two population of male and female are equal in perception as well as other factors related to it, so it is observed that there is no significant difference in obtained perception scores towards CALL in Iranian EFL teachers between two groups of female and male teachers.

In the other words, the gender has no affect on the perceptions of teachers towards the application of CALL. The key results of this analysis are presented in Table 2.11. The results demonstrate that in this case of study there are no significant differences in all the constructs between two genders (male and female). 
Table 2.11: Obtained T-test result on differences in gender and perception towards CALL in Iranian EFL teachers

\begin{tabular}{|c|c|c|c|c|c|c|}
\hline & \multicolumn{2}{|c|}{ Levene's Test for Equality of Variances } & \multicolumn{3}{|c|}{ t-test for Equality of Means } \\
\hline & & $\mathrm{F}$ & Sig. & $\mathrm{t}$ & df & Sig. (2-tailed) \\
\hline \multirow{2}{*}{ Overall perception } & Equal variances assumed & 1.367 & .245 & -.164 & 94 & .870 \\
\hline & Equal variances not assumed & & & -.165 & 93.852 & .869 \\
\hline \multirow{2}{*}{ Affective } & Equal variances assumed & .087 & .769 & .250 & 94 & .803 \\
\hline & Equal variances not assumed & & & .248 & 89.213 & .804 \\
\hline \multirow{2}{*}{ Cognitive } & Equal variances assumed & .129 & .721 & -.471 & 94 & .639 \\
\hline & Equal variances not assumed & & & -.469 & 92.036 & .640 \\
\hline \multirow{2}{*}{ Behavioral } & Equal variances assumed & .362 & .549 & -.159 & 94 & .874 \\
\hline & Equal variances not assumed & & & -.160 & 93.976 & .873 \\
\hline \multirow{2}{*}{ Advantage } & Equal variances assumed & .504 & .479 & -.972 & 94 & .333 \\
\hline & Equal variances not assumed & & & -.975 & 93.995 & .332 \\
\hline \multirow{2}{*}{ Compatibility } & Equal variances assumed & .115 & .735 & .317 & 94 & .752 \\
\hline & Equal variances not assumed & & & .320 & 92.294 & .750 \\
\hline \multirow{2}{*}{ Complexity } & Equal variances assumed & 1.428 & .235 & -1.337 & 94 & .184 \\
\hline & Equal variances not assumed & & & -1.329 & 89.362 & .187 \\
\hline \multirow{2}{*}{ Observability } & Equal variances assumed & .012 & .912 & .109 & 94 & .914 \\
\hline & Equal variances not assumed & & & .108 & 92.815 & .914 \\
\hline \multirow{2}{*}{ Overall attributes } & Equal variances assumed & 11.437 & .001 & -.862 & 94 & .391 \\
\hline & Equal variances not assumed & & & -.882 & 76.776 & .381 \\
\hline \multirow{2}{*}{ Cultural perceptions } & Equal variances assumed & .710 & .402 & .825 & 94 & .412 \\
\hline & Equal variances not assumed & & & .820 & 88.982 & .415 \\
\hline \multirow{2}{*}{ Computer competence } & Equal variances assumed & .005 & .946 & 1.041 & 94 & .300 \\
\hline & Equal variances not assumed & & & 1.043 & 93.788 & .300 \\
\hline \multirow{2}{*}{ Overall access level } & Equal variances assumed & .183 & .670 & 1.658 & 94 & .101 \\
\hline & Equal variances not assumed & & & 1.663 & 93.986 & .100 \\
\hline
\end{tabular}

Note: F: Frequency, Sig: Significance.

\section{Discussion}

The main goals of this study were first to explore the overall specific perception of Iranian EFL teachers in the application of computer assisted language learning and second to investigate this perception with some independent variables that affect teachers' use of CALL program and finally to investigate the differences in teachers' perception towards the use of CALL in terms of gender. The result showed that there is a great interest and willingness and relatively high positive perception to use of computer and technology among the Iranian teachers.

This result has a significant educational importance, as Garcia and Arias (2000), claim, the providing a list of content is not the main goal of education but teaching them learn autonomously and maintaining continuous independent learning perceptions to meet their needs and wants takes itself more priority.

Therefore, remarkable numbers of organizations and institutions to meet the prospective requirements have been adapting their curricula for students and teachers.

Most teachers in the study believe that the computer can be a valuable learning instrument to enhance the quality of students' learning, sharing information and communicating with target language speakers.

However, they seem to have issues and related problems in using the computers in the classroom. Context oriented reasons for not using technology and specially the computers from the participants view include limited technical support, limited class hours, limited computer facilities, and inappropriate class size.

Regardless of the difficulties they have in their teaching situations, then, teachers and instructors need to find ways of working around the situations to provide better EFL instruction. The potential of the computer and technology can be enormous if they make efforts to find and use computer resources with positive perception.

Results obtained from preceding study showed that the perception of teachers about the level of computer attributes had an extremely solid and specific correlation with the extent of technology and computer utilization. This is in accordance with some other studies.

According to Rogers (2003), technology related innovations offering more relative advantage, compatibility, simplicity, and observability will be adopted faster than other innovations. Hence, training EFL teachers to enhance their 
understanding about new technology tools and computer attributes is crucial, because they are fundamentally related to individuals' adoption intentions.

Further, results from this study demonstrated that teachers had right and positive enough cultural perceptions of CALL in the context of Iranian community and English language institutes.

Such instructors and language teachers could utilize innovation in technology and make a suitable situation in society and culture to the integration of computers and technologies in English language institutes and schools. These kinds of cultural perception cooperate and relate the teachers' prosperity to their ability to create and affect qualities and standards. At that point, awareness of peoples 'culture and the cultural values is as essential as awareness of the innovative advantages. Responsible and dutiful Teachers who are in charge of adopting and implementing computer and its educational innovations in English language institutes and schools must be mindful of its significant impacts in terms of societal and organizational cultural effects that it have on it.

Moreover, this has resulted in the finding of this research that gender did not have any effect on Iranian teachers' perceptions towards the application of CALL.

This results and findings are not in line with some past conducted researches that discovered difference between gender and computer perception of the teachers in educational context (Yıldırım, 2000, Ray, Sadık, 2006, Sormunen and Haris, 1999).

Yet In one way or another, some different studies expressed that perception directly was not related with gender (DeBlassioa \& Bell, 1981; 2008; Bebetsos \& Antoniou, 2008, Deniz, 2007; Akbulut) and this point is what supports the obtained results of this study. The primary reason of this conclusion probably can emerge from common usage of new technology specially computers in all ranges from dealing to business and shopping that is alluring, interesting and valuable for both male and female.

\section{Conclusion and Pedagogical Implications}

This study examined how Iranian EFL teachers see the utilization of technology and computer related tools in language learning and teaching with focus on the perceptions of teachers towards the application of CALL in general and the influential factors related to using CALL programs at English language institutes in Kurdistan province, Iran.

In the recent decades English language teaching has paid more attention towards teachers 'perception in the application of CALL as an important factor since technology integration in education generally has been accepted (Rogers, 1995; Watson, 1998; Woodrow, 1992).

Based on insights from the previous researchers, it can be assumed that teachers have appositive perception for using CALL.

The finding of the present study supported this assumption and results showed that there is a high positive perception toward CALL among the Iranian teachers. They had more positive affective and cognitive perception than behavioral perceptions.

Another finding of the study distinguished the degree to which computers has been used by Iranian EFL teachers and investigated the relationship between quantities of variables related to CALL application.It appears that teachers ought to be mindful of the place of CALL in their educational context and their work and get suitable abilities to utilize and coordinate technology into the English language institutes and schools.

Additionally, findings of this study demonstrated that to make a critical effect on the extent of technology and computer application, the computer access in a more high level is required. Indeed, teachers in accordance to the present technology centaury and application of it in all aspect of life ought to have necessary access to computer advances in English language institutes, or any educational location in which the level of access to information and teaching instruments is essential. In addition, Investment needs to be made accessible to buy computer equipments both hardware and software.

For teachers to do this right, they must guarantee the access to required equipments and upgraded hardware and software. English language institutes and educational funds must be invested for reach to an appropriate training and necessary upgrades in software and hardware related to this domain. The other finding from present study demonstrated that the CALL perception of teachers in computer attributes had a nearby and solid association with the extent of computer application.

Subsequently, to enhance teacher's perception and promote his/her background knowledge towards CALL and using new technologies in teaching, policy makers ought to bring teachers' knowledge up to date in using equipment and computer software, hardware, and Internet. Likewise, various CALL tools should be presented to teachers to enhance their perceptions. To attain to this, teachers ought to be motivated to utilize innovations in technology, software and 
hardware prepared for educational purpose in their teaching and educational tasks. In such a way, teachers will understand the capability of the related technology in language teaching and as teachers and instructional leaders perceive positive effect of computers on the process of their teaching.

Another finding is that, the specific regard and attention to cultural beliefs and the kind of confidence and commitment in using technologies in a society and perception and their effects on CALL are remarkably significant and has its particular and interesting place in developing countries (Loch, 2003) since this socio-cultural factors in such countries may put CALL transfer at risk and is to some extent different in one culture to another (Albirini, 2006). " Duplicating strategies from other developed countries without any consideration about cultural adaptations of technologies might be less effective and successful" (Kousha \& Abdodi, 2004). As indicated by Fleron (1977),Just installation of the new technology and the explanation and getting instruction in using it, doesn't finished implementation of it, as a matter of fact, in any time innovation in technology should be recognized and confirmed by the receiving community(Asemi, 2006). The truth of the norms and the values of community must not deny. The results and findings adopted from present study demonstrated that teachers mainly had definite and true agreements in terms of cultural perceptions of using CALL in community and English language institutes. Such teachers could utilize new technology and make a suitable domain in their place and culture to the incorporating of technology into English language institutes and generally in educational contexts. Therefore, English teachers who are in charge of applying and using technology in English language institutes must be mindful of its considerable cultural effects socially and organizationally.

The consequences of the result of the present study recommend that just coordinating and applying computer technology in English language teaching and training and making the essential instruments and environment available in their place are not sufficient to start teaching by using of these kinds of technology and computers. The obtained findings conducted from research, suggest that there is a need for training and access to technology for both students and teachers. As well as, for effectiveness in using computer technology in language instruction some technical support should be expanded. The findings in addition demonstrate the need for a typical educational program.

The obtained findings of the preceding study also demonstrate that teachers should be made mindful of the advantages of the technology and specially application of computers in language teaching instruction.

Throughout the process of integrating of the technology, the related and required information about the advantages of computer programs in line with language instruction is needed to be provided for teachers. This important issue needs the appropriate supervision and suitable help from those who has a high degree of knowledge or skill and trainers in the field. These relevant subjects and specific factors have also been considered by Higgins \& Kassen (1997).

According to the results and findings in the related literature the significance of on-going assessments in the process of learning and teaching also have been reported (Brown, 1995; Graves, 2000).

\section{References}

Abas, Z. W.(1995a).Attitudes towards using computers among Malaysian teacher education students. In J. D. Tinsley, \& T. J. van Weert (Eds.), World conference on computers in education VI: WCCE_ 95 liberating the learner (pp. 153-162). London: Chapman \& Hall.

Agbatogun, O.A., (2006). Attitude of teachers towards the integration of computer education into secondary school curriculum. Journal of Research Curriculum Teaching, 1: 1-20

Ahangari,S.,Sioofy,M. (2013). The Effect of Computer Assisted Cooperative Language Learning on Iranian High School Students' Language Anxiety and Reading Comprehension. International Journal of Foreign Language Teaching \& Research, 1.

Ahmed, K., Corbett, G., Rogers, M., \& Sussex, R. (1985). Computers, language learning and language teaching . Cambridge: CUP.

Akbulut,Y. (2008). Exploration of the attitudes of freshman foreign language students toward using computers at a turkish state university. The Turkish Online Journal of Educational Technology, 7, 18-31.

Albirini, A. (2004). An exploration of the factors associated with the attitudes of high school EFL teachers in Syria toward information and communication technology. Unpublished doctoral dissertation, Ohio State University.

Albirirni, A. (2004).Teachers' attitudes toward information and communication technologies: the case of Syrian EFL teachers. Computers \& Education 47 (2006) 373-398.

Al-Juhani, S. O. (1991). The effectiveness of computer-assisted instruction in teaching English as foreign language in Saudi secondary school. Unpublished doctoral dissertation, University of Denver, Denver, CO

Al-Shammari, M. (2007).Saudi English as a foreign language: Learners' attitudes toward Computer-Assisted Language Learning. Unpublished doctoral dissertation, West Virginia University.

Arkin, E.I. (2003). Teachers' attitudes toward computer technology use in vocabulary instruction. Unpublished master's thesis. The Department of Teaching English as a Foreign Language, Bilkent University, Ankara, Turkey.

Avraham, L. (2005). Differences in the way males and females perceive computers, retrieved from

Aydin, S. (2013). Teachers' perceptions about the use of computers in EFL teaching and learning: the case of Turkey. Computer 
Assisted Language Learning 26(3), 214-233.

Ayres, R. (2002). Learner attitudes toward the use of CALL, Computer Assisted Language Learning, 15 (3): 2, 1-249.

Barani, \& Seyyedrezaie, S. Hassan (2010). English for the students of computer science. Tehran: Rahnama Press.

Bordbar,F. (2010). English teachers' attitudes toward computer-assisted language learning . International Journal of Language Studies (IJLS), 4(3), 179-206.

Brierley, W. \& Kemble, I. (1991). Computers as a tool in language teaching. West Sussex: Ellis Harwood Limited.

Chapelle, C. A. (2010). The spread of computer-assisted language learning. Language Teaching 43(1), 66-74.

Darus,S., W. Luin,H. (2007).investigating teachers' use of computers in teaching English: A case study. Universiti Kebangsaan Malaysia, 1-18.

Dashtestani,R.(2012).EFL teachers' knowledge of the use and development of computer assisted language learning(CALL) materials. Teaching English with Technology, 14(2), 3-27

Dashtestani,R.(2012).Implementation of CALL in EFL courses: Iranian EFL teachers' attitudes and perspectives. Jaltcalljournal, 8, 5570.

Dashtestani,R.(2013). EFL teachers' and students' perspectives on the use of electronic dictionaries for learning English. CALL-EJ, 14(2), 51-65.

Soner Y, (2000) Effects of an Educational Computing Course on Preservice and Inservice Teachers. Cambridge: Cambridge University Press. A discussion and analysis of attitudes and use. Journal of Research on Computing Education, 32(4), 479- 495.

Fardy, M., Noori Shorabi, H., \& Mohammadi, Y. (2012). The Effect of using computer-assisted language learning (CALL) on the Reading Comprehension of Narrative Texts for the Iranian University Male Freshmen. Iranian EFL Journal 8 (1), 292-300.

Garland, K. J., \& Noyes, J. M. (2005). Attitudes and confidence towards computers and books as learning tool: a cross- sectioned study of student cohorts. British Journal of Educational Technology, 36(1), 85-91.

Ghalami Nobar, A., \& Ahangari, S. (2012). The Impact of Computer Assisted Language Learning on Iranian EFL Learners' Task-Based Listening Skill and Motivation. Journal of Academic and Applied Studies 2 (1), 39-61.

Ghasemi, B., Hashemi, M., \& Haghighi Bardine, S. (2011). The capabilities of computers for language learning. Procedia-Social and Behavioral Sciences, 58, 28-52.

Gündüz,N. (2005). Computer Assisted Language Learning (CALL). Journal of Language and Linguistic Studies,1,193- 2014.

Hashemi, M., \& Azizinezhad, M. (2011). Computer Assisted Language Learning Freedom or Submission to Machines? Procedia-Social and Behavioral Sciences, 28, 832-835. http://eserver.org/course/spring97/76100o/contributions/avraham/

Huang, H. M., \& Liaw, S. S. (2005). Exploring user's attitudes and intentions toward the web as a survey tool. Computers in Human Behavior, 21(5), 729-743.

Hubbard, P. (2008). CALL and the future of language teacher education. CALICO Journal 25(2), 175-188.

Jafarian, K., Soori, A., \& Kafipour, R. (2012). The Effect of Computer Assisted Language Learning (CALL) on EFL High School Students 'Writing Achievement. European Journal of Social Sciences 27 (2), 138-148. 